\title{
O IMPERATIVO ESTÉTICO VOCATIVO NA ESCRITA FENOMENOLÓGICA
}

\author{
The Vocative Aesthetic Imperative in Phenomenological Writing \\ El Imperativo Estético Vocativo en la Escritura Fenomenológica
}

Eduardo José Marandola JúNIOR

\begin{abstract}
Resumo: A fenomenologia é um projeto incompleto, sempre a caminho. Neste pensar constante, um dos desafios ainda pouco enfrentados é o da escrita fenomenológica que, a despeito das mudanças epistemológicas encampadas pelos fenomenologistas, não raro mantém sua escrita indistinta do restante das ciências. No entanto, há necessidade de busca de outras formas de dizer, para superar a limitação da linguagem moderna, já apontada pelos fenomenológos, em permitir que o Ser se revele. É neste sentido que Max van Manem fala do vocativo como uma necessidade para o texto fenomenológico, adotando a enunciação como sentido principal da escrita e, consequentemente, da leitura. Este se expressa como um imperativo estético, que se desdobra em diferentes modos de escrever que permitem que o intuitivo, o sensível e o não-dizível encoberto possa se desvelar, no ato de escrita-leitura. Para contribuir para o enfrentamento deste desafio pela Geografia, navego pela fenomenologia dos sentidos de Michel Serres, um mestre do texto vocativo em diferentes facetas, para compreender o sentido hermenêutico da escrita fenomenológica.
\end{abstract}

Palavras-chave: Hermenêutica; Fenomenologia geográfica; Linguagem.

Abstract: Phenomenology is an incomplete project, always on the way. In its process of constant thinking, one of the challenges still barely confronted is the phenomenological writing, which, despite the epistemological changes promoted by phenomenologists, often maintains indistinct when compared to other sciences. However, there is a need to search for other ways of saying, to overcome the limitation of the modern language, as pointed out by phenomenologists, allowing the Being to reveal itself. In that sense, Max Van Manem mentions the vocative as a demand to the phenomenological text, adopting the enunciation as the main direction of writing and, consequently, reading. This vocative appears as an aesthetic imperative that unfolds in different ways of writing, allowing the hidden intuitive, sensitive and not speakable to be revealed in the act of writing-reading. To contribute in tackling this challenge through Geography, I navigate Michel Serres' phenomenology of senses, a master of the vocative text in it is different facets, to comprehend the hermeneutic sense of the phenomenological writing.

Keywords: Hermeneutic; Geographic phenomenology; Language.

Resumen: La fenomenología es un proyecto incompleto, siempre en camino. En este pensar constante, uno de los desafíos aún poco enfrentados es el de la escrita fenomenológica que, pese a las mudanzas epistemológicas seguidas por los fenomenólogos, no es raro que mantenga su escrita indistinta del resto de las ciencias. Sin embargo, existe la necesidad de buscar otras formas de decir, para superar la limitación del lenguaje moderno, ya establecido por los fenomenólogos, en permitir que el Ser se revele. Es en este sentido que Max Van Manem habla del vocativo como una necesidad para el texto fenomenológico, adoptando la enunciación como un sentido imperativo estético, que se desdobla en diferentes modos de escribir que permiten que lo intuitivo, sensible y no-nombrable encubierto se pueda desvelar, en el acto de escritura-lectura. Para contribuir para el enfrentamiento de este desafío por la Geografía, navego por la fenomenología de los sentidos de Michel Serres, un maestro del texto vocativo en diferentes facetas, para comprender lo sentido hermenéutico de la escritura fenomenológica.

Palabras-clave: Hermenéutica; Fenomenología geográfica; Lenguaje.

À medida que as semanas decorriam tornava-se evidente que a guerra teria de ser interrompida. Havia como que uma saturação, diremos, obscenamente, estética: certo modo de a cidade se fragmentar tornarase irritante, primeiro aos olhos e, pouco a pouco, intolerável. Não era pois tanto uma imposição moral ou de sentimentos firmes que regressavam; tratava-se acima de tudo de um cansaço no olhar: a repetição das imagens tornava-se excessiva; a exaltação medrosa em frente a um cadáver desaparecera, a violência explícita abandonara o espaço central das narrativas para ser integrada, de modo objetivo e neutro, em relatórios. O mais um dito em frente aos cadáveres tornara-se mais violento que a própria matéria, ali, caída, matéria desprovida já do algo humano que desaparecera da mesma forma imediata e misteriosa com que aparecera,

no meio da família, no dia de seu nascimento. [...] Era esse mais um que estava a terminar com a guerra. Gonçalo Tavares, A máquina de Joseph Walser 


\section{Degeneração e significado}

Desculpem, caros amigos, estou em processo degenerativo. A escrita se coloca como espera desenfreada, como eco retumbante, dentro-fora-dentro-fora-dentro-entre. Não é apenas a proximidade ou a necessidade da construção: é a adoção de uma voz, que diz, e vocaciona, que enleva e envolve, anunciante.

Mas quem ouve enquanto fala? O desafio é o da sensação que se propaga, aquela que me invade, poder ser vocacionada como algo que reverbera, mais ainda. A razão ou este corpo não devem ser amortecedores de sensações, onde as ondas que ricocheteiam pelo mundo venham se acalmar. Este corpo, sensível e pulsante, deve ser ele próprio o eco e o que ressoa.

Para isso é necessário assumir uma voz. Não uma voz singular, única, atomizada. Uma voz que se deixa transpassar, com a ação de deixar-ser. A fenomenologia, de partida, se propõe um pensar-sentir, mesmo que em variados grados. Pode ser mais idealista com Husserl, mais perceptiva ou carnal com Merleau-Ponty, mais ontológica com Heidegger, mas nunca perde o sentido primeiro de crítica a uma postura racionalista do conhecimento. A ênfase na experiência é recorrente e um dos caminhos para este permitir ser invadido pelo mundo, à maneira de Merleau-Ponty (2012).

No entanto, continua sendo um pensar e este pensar, pelo esforço teórico de desocultamento e de desvelar os sentidos, soterrados por tantas camadas de mediação e do excesso de dizer, por vezes se torna um projeto incompleto, irrealizado. De que modo? Às vezes sentimos que o esforço de suspender os sentidos, colocando entre parênteses - como o queria Husserl -, escavando esta polifonia megafônica dos sobre-sentidos ensurdecedores, já é tão grande que nos falta fôlego para, por fim, ouvir, deixar-se desvelar os fenômenos, como insistia Heidegger. O trabalho hermenêutico e as sucessivas compreensões em seu círculo muitas vezes não se aprofunda, deixando a tarefa igualmente inacabada.

Esse esforço é tanto mais sentido e complexo em nossa rotina universitária, com nossos prazos, tempo que se esvai, com tanto para fazer, tendo de apresentar produtos e resultados. Muitos temem a perda da qualidade e a impossibilidade de um pensar sincero, autêntico.

Por isso meu processo de degenerescência com a escrita, por isso esta inquietação que me arrebata a pensar o sentido da fenomenologia enquanto fazer, em direção a uma fenomenologia que se realize como caminho e abertura, mas que exerça sua potência de pensar. E para isso, me parece, duas coisas têm se tornado muito fortes para mim, as quais gostaria de compartilhar e aprofundar em forma de escritos futuros:

1. A necessidade de incorporar o fazer fenomenológico à nossa escrita;

2. A necessidade de um pensar-sentindo.
Quanto ao primeiro, na realidade, envolve a preocupação não apenas com a escrita, mas também com a leitura, as conversas e o pensar propriamente. Por vezes um trabalho que toma a fenomenologia como método ou como fundamento epistemológico mantém sua apresentação e sua escrita como as de um trabalho cuja estrutura é a da ciência moderna, no sentido constituído desde Galileu, Descartes e Bacon (Stengers, 2002; Husserl, 2012), como uma nova episteme que estabeleceu, como na leitura foucaultiana, a separação entre palavras e coisas (Foucault, 2007). Isso nos traz o problema da linguagem, cujo enfrentamento é central nos desdobramentos da fenomenologia e da própria filosofia contemporânea, já que toca o cerne do problema do conhecimento que enfrentamos: como dizer aquilo que sentimos? Como trazer a experiência vivida para um texto sem degenerá-la, transformando-a em dados objetivos a serem apreendidos? Como falar da afetividade e das volições utilizando uma linguagem que é fragmentadora e que nos impossibilita, de saída, expressar o sentido vivido dos fenômenos?

Penso que este seja um problema central, capital para todos nós, o que nos convoca a pensar um texto e uma escrita em que não podemos tomar como meta revelar o Ser, ou explicar a essência dos fenômenos. Antes, a escrita teria de ser uma artesania que, como algo vivo e pulsante, permitisse, ela própria, uma experiência. Neste caso, os sentidos e essências poderiam ser intuídos pelo leitor a partir da experiência de leitura do texto.

Isso nos leva à segunda questão, sobre a necessidade de um pensar-sentindo. Em nosso esforço de apropriação da fenomenologia para os estudos geográficos temos nos dedicado muito à reflexão teórica e no aprofundamento da compreensão do pensamento de muitos autores, como Gaston Bachelard (Gratão, 2012), Martin Heidegger (Marandola Jr., 2012; 2016; Dal Gallo, 2015; Dal Gallo \& Marandola Jr., 2015; Bernal, 2015; Galvão, 2016) e Edmund Husserl (Ferreira, 2016), além de outros ainda em processo de investigação, como P. Ricouer, E. Lévinas, C. Romano, entre outros. Isso é fundamental para a construção de um outro caminho ao posto pela ciência moderna. No entanto, é igualmente fundamental que este movimento não nos leve ao mesmo racionalismo abstrato e abstracionista. Por isso a evocação de um pensar-sentindo de Martin Heidegger (reverberando Nietzsche), já presente na análise existencial e reforçada posteriormente em sua guinada para o poético (Heidegger, 2001a; 2001b; 2012a; 2012b), de um outro pensar, que não é ação racional apenas, mas se dá na proximidade do Dasein. Este se remeteria à ideia de um pensar ligado à intuição das essências e, sobretudo, à tarefa de deixar o Ser revelar-se; uma atitude de espera ligada ao sentir (Heidegger, 2001c; 2001d).

Este pensar-sentindo, no entanto, será tão mais potente quanto estivermos abertos à possibilidade da invasão do mundo, naquilo que Heidegger (2012b) chama de mútua doação. Tomando a situação existencial como circunstancialidade, deixar-se ser invadido pelo mundo não é uma 
relação passiva: antes, envolve conceber o conhecimento como relação, sempre situada, simultânea e mutuamente aberta (Malpas, 2008). Nossa racionalidade opera muitas vezes como muros de isolamento, ou bolhas de sentido. Quando menos esperamos, construímos representações das coisas e caímos novamente na atitude natural. Parece-me igualmente necessário ao aprofundamento teórico a imersão sem reservas no mundo, a abertura para experiências diversas e o exercício desse ser-e-estar-no-mundo constante, via sentidos. M. Merleau-Ponty (2007) chamava atenção para esta forma de ser invadido pelo mundo, manifesto na paisagem, ideia desdobrada por Jean-Marc Besse (2006) e por Éric Dardel (2011).

São duas tarefas, portanto, da mais alta importância e da mais alta dificuldade. No entanto, as vejo como fundamentais para não reproduzirmos a fragmentação moderna sujeito-objeto e para que a força da razão não se torne aquela que cala toda vivacidade e diversidade pululante do mundo vivido; antes, que se alie ao sentir, à emoção e à intuição em nossa compreensão. Por isso um pensar-sentindo se faz necessário.

Neste texto começarei a refletir sobre elas, em um único movimento: navegando pela escrita vocativa da fenomenologia dos sentidos de Michel Serres, procurando compreender as possibilidades desveladoras do texto e suas múltiplas possibilidades de torná-lo aberto ao movimento hermenêutico. Longe de pensar um modelo de escrita ou um formato pré-definido, este texto se constitui ele mesmo como uma experiência e um experimento, na expectativa de exercitar outras formas de escrita e compreender, no caso de Serres, quais elementos permitem que seu texto filosófico seja ao mesmo tempo rigoroso e vívido, denso conceitualmente e composto por uma plêiade de experiências e imagens.

O que se desvela não é apenas a necessidade do sentido vocativo do texto (o que o permite expressar e compartilhar experiências), como a demanda por uma hermenêutica que torne o texto potente e prenhe de significados. Nesta hermenêutica está também a sua potência como desvelador de sentidos, entrelaçando narrativa e experiência ${ }^{1}$.

\section{Narrativas e experiências}

Quando me tornei aluno de pós-graduação, na Unicamp, era muito jovem e tinha uma vontade infinita de conhecer. Interessava-me por tudo em uma intensidade infinita, especialmente livros, lugares e pessoas. Tinha consciência plena de tudo que me faltava conhecer, e uma vontade inesgotável de saciá-la.

\footnotetext{
Embora não seja foco deste artigo, Paul Ricouer abre, em Tempo e narrativa, um dos caminhos possíveis para refletir sobre a escrita fenomenológica e suas relações com a experiência, o tempo e a memória (RICOEUR, 2010), o que pretendo refletir em outros escritos.
}

Foi assim, por exemplo, que passei a frequentar as bibliotecas da Unicamp e da Unesp, em Rio Claro, em busca dos periódicos clássicos da Geografia. Naquele antigo prédio da Rua 10, hoje desativado, passei horas muito prazerosas entre velhas estantes, velhas escrivaninhas, velhas bibliotecárias e velhas cadeiras. Sentia-me privilegiado, tendo a oportunidade de explorar tesouros, de conhecer textos que apenas havia visto referências. Era um mineiro garimpando em volumes encadernados.

Ali naquelas estantes descortinava-se para mim boa parte de toda uma geografia que era mitológica até então: os indícios ganhavam materialidade, os nomes, concretude, os textos, extensão, mas também finitude. Ao mesmo tempo, portanto, que havia o maravilhamento e o encantamento, havia também uma espécie de apropriação, pois os textos tinham fim, limites, lacunas, portas abertas e caminhos a percorrer. Ao final de meses, era nítido para mim que havia muito mais a ser feito do que aquilo que já estava concluído.

Mas não era isso o que eu queria dizer.

$\mathrm{O}$ que mais me chocava nestas primeiras buscas, era encontrar muitos textos sobre percepção, que na época eu tinha como textos humanistas, com uma linguagem tão técnica quanto qualquer outro texto neopositivista. Encerrar a percepção em gráficos ou em frequências descritas em porcentagens causava um estranhamento que à época não conseguia nomear. Era um dos ruídos em meio ao maravilhamento: uma das aberturas que se anunciavam.

Por muito tempo, essa proximidade formal era uma maneira de aceitação ou de inserção de estudos que se preocupavam com novos temas, mas que não assumiam as consequências desta escolha em todas as suas dimensões. Eu mesmo, apesar de me preocupar com uma adoção mais completa da fenomenologia em meu fazer, só pude enfrentar tal desafio de forma mais direta bem recentemente.

Michel Serres certamente não foi o primeiro autor a me despertar este desejo por fazer da tessitura do texto um trabalho de artesão, criativo e heterodoxo, ficcional e poético, sensível e profundo. Mas certamente ele é responsável por um empurrão definitivo nesta busca por assumir o enfrentamento do desafio da linguagem e da mundanidade do pensamento, ao mesmo tempo.

Mas que força podem ter experiências particulares para a elucidação de temas e problemas complexos e contemporâneos? E como trazê-las de forma a não serem anedotas, mas potências que revelam o sentido dos fenômenos?

Esta talvez seja uma das grandes potências da fenomenologia e nós, por vezes, a enfraquecemos com racionalismos. Por que partir de uma explicação teórica e não de uma narrativa?

Serres é um filósofo que primou por não se prender a uma forma de pensamento. Para ele, a filiação rígida a sistemas de pensar, como as disciplinas ou a filosofia, conduziam a conflitos e tensões que eram contraproducentes do ponto de vista humano e social (Serres, 1996). 
E é justamente nesta postura que reside sua potência em trazer a questão dos sentidos e da sensibilidade de forma radical e de construir seus textos em diferentes formatos, com mitos, narrativas (ficcionais ou não), pinturas, reflexões e pensamentos. Van Manem (2014, p. 164-165) afirma que Serres executa, em sua escrita, uma verdadeira análise fenomenológica. "A análise é o escrever". ${ }^{2}$ Isso se deve, sobretudo, ao caráter vocativo do texto de Serres, como podemos apreciar neste trecho de Os cinco sentidos: filosofia dos corpos misturados, no qual escreve sobre as relações entre ciências humanas e exatas.

Deus não engana nem trapaceia. Os objetos, nas ciências exatas, ficam estáveis. O homem engana e trapaceia, mais e mais que desaparece, às vezes, como Zeus sob a pele do touro, como Hera sob o ferrão do moscardo. Ora, aquele que trapaceia e engana faz isto porque quer ganhar. Portanto, o primeiro atributo de Deus consiste em não fazer caso de ganhar.

Afastem-se das apostas, desdenhem a vitória ou a perda, entrarão em ciência, em observação, em descober-

ta, em pensamento. (Serres, 2001, p. 39)

Serres evoca os sentidos a partir tanto de elementos da mitologia quanto da situação que cria, ao considerar as ciências humanas como enganadores e apostadores. Vocação, evocação, reinvocação, invocação, convocação e provocação são métodos de escrita mencionados por Van Manen (2014) como possibilidades de escrita fenomenológica. Na realidade a vocação é o sentido mais amplo, que tem relação com a construção de uma voz do texto, como em um diálogo, que torna a própria escrita viva, vocacionada por uma existência que anima o texto de tal maneira que o leitor se sente em diálogo ao realizar a leitura. Trata-se de uma escrita reflexiva, pensante, que ressoa no leitor pela força sensível e pela plausibilidade das experiências compartilhadas.

Já a reinvocação se manifesta quando o texto traz para o presente, para a leitura, uma experiência vivida, mas permitindo ao leitor revivê-la: é o sentido do vivido trazido pela linguagem. A linguagem, em seu caráter hermenêutico, permite que a descrição de experiências seja evocativa a partir de experiências do leitor ou pela verossimilhança e factibilidade do relato. A vivacidade traz novamente a possibilidade da experiência, via sentido.

Essas narrativas podem ser ficcionais, fatuais ou imaginadas, não há diferença, pois sua potência está na reinvocação que realizarão, ou seja, nos sentidos que trarão à tona (Van Manen, 2014). O fundo de onde estes sentidos estão sendo reinvocados não é outro senão da própria experiência de mundo, pessoal e compartilhada, e por isso fábulas ou acontecimentos históricos também são potentes em reinvocações.

\footnotetext{
2 Não deixa de ser curioso a defesa de uma escrita vocativa e criativa justificando-a como uma "verdadeira análise".
}

No caso da evocação, no entanto, o movimento é o de trazer para fora no sentido de recriar, reverberando os sentidos a partir da própria escrita. Implica utilizar a linguagem para reordenar sentidos, sendo fundamental a imaginação. No segundo trecho trazido da obra de Serres, temos a evocação do sentido de Atlas, reinventando-o, assim como o de Geografia. É um trazer à proximidade, como afirma Van Manen (2014), convocando-a, chamando-a manifestar-se.

Eis agora a questão fundamental de qualquer atlas: de que é que se deve traçar um mapa? Resposta evidente: dos seres, dos corpos, das coisas... que não conseguimos conceber de outro modo. Por que é que, com efeito, nunca desenhamos as órbitas dos planetas, por exemplo? Porque uma lei universal prevê as suas posições; de que é que nos serviria um roteiro neste caso de movimentos e situações previsíveis? Basta deduzi-los da sua lei. Pelo contrário, não há qualquer regra que prescreva o recorte dos rios, o relevo das paisagens, a planta da aldeia onde nascemos, o perfil do nariz ou a impressão digital do polegar... Aí estão singularidades, identidades e indivíduos, infinitamente afastados de qualquer lei; trata-se de existência, e não de razão, afirmavam os filósofos.

Desde então, as simulações a que chamamos retratos, reproduções ou representações passaram, durante muito tempo, por atrasos para os princípios, impossíveis de encontrar ou ausentes. As ciências pesadas pelas boas razões e, por vezes, mesmo as humanas pelas más, cumularam de desprezo os geógrafos, os anatomistas, os urbanistas... escarnecendo da distância entre a verdadeira geometria, demonstrativa, e aquela que se praticava no terreno... vaga. A lei rigorosa, finalmente, é a melhor das memórias, sem stock e, portanto, leve, quando é necessário desenhar os traçados, e depois conservá-los, para manter a recordação. Ora os métodos algoritmos, antigos na medida em que datam dos babilónicos, e contudo novos desde que surgiram os computadores, também eles cosendo dois mundos e dois tempos, presidem às tecnologias de simulação que abordam a existência com uma extraordinária proximidade. Eles sugerem, por vezes, novos caminhos de passagem do local ao global de cuja fiabilidade a razão clássica, totalmente absorvida com o abstracto, luminosamente global, não suspeitava. Como os algoritmos procedem, no sentido absoluto do termo, isto é, descrevem processos e métodos através de conjuntos de caminhos, pode dizer-se que a sua razão é cartográfica. Ao proceder passo a passo, mas à velocidade da luz, a simulação alcança aquilo que designávamos por razão.

Lição do novo atlas: esta nova geografia vale bem a mais pesada das antigas ciências; e dado que a filosofia as imitava, ei-la subitamente envelhecida! (Serres, 1997, p. 17-18) 
Esta evocação de sentidos o situa para dele emanar a força da evocação. A forma deste Atlas, evocado, não é o de uma representação pois, enquanto evocação, é o próprio sentido situado que se apresenta de forma autêntica, no contexto da evocação.

A invocação, compreende a intensificação dos sentidos e da sensibilidade. O termo traz o sentido de convocar, implorar, conjurar, como uma encantação. É muito utilizado em linguagem poética, como em Bachelard (2003, 2009) e seus estudos sobre a poética do espaço e do devaneio. A invocação tem o objetivo de intensificar o sentido de forma a produzir uma forte sensação no leitor. Esta sensação, que pode ser uma imagem criada durante a leitura, é a potência de revelação do sentido do fenômeno.

A convocação é o método no qual o texto utiliza capacidade de fazer aparecer os sentidos a partir dos sentidos empáticos, envolvendo uma cumplicidade que convoca o leitor a partilhar o sentido e o texto, com sentido ético que convoca à ação.

Por fim, o método provocativo é aquele que por colocar em cheque as compreensões do leitor, fazendo-o refletir e duvidar de suas próprias compreensões, cria a possibilidade de uma epifania, que de repente explode durante a leitura (Van Manen, 2014). Provocação carrega o sentido de desafiar, levar adiante, incitar, o que implica que estes textos produzem ações.

Em todos os casos, a força de qualquer destes métodos está na experiência, não em um repertório de representações. O texto será tanto mais vocativo quanto tiver a presença do autor, no sentido de fazer-se esta voz em diálogo. Os diferentes métodos não são excludentes, é claro, e serão mais adequados a depender do próprio fenômeno a ser desvelado. Assim, uma escrita vocativa é pensante e sensível ao mesmo tempo, sempre fundada na experiência.

Michel Serres aliou de forma exemplar estas formas narrativas. Seu texto é vivo, pulsante, envolvendo seu leitor para sentir, sendo este seu caminho para o pensar. Em Os cinco sentidos: filosofia dos corpos misturados, Serres (2001) enfrenta um tema difícil de exprimir em palavras: a potência dos sentidos enquanto mistura (sinestesia), o que implica a mistura também dos elementos (homemnatureza) e dos conhecimentos (ciências humanas-ciências exatas). O cerne de seu pensamento está no corpo: um corpo-vivo que pensa e sente, que é expressão própria desta indefinição entre dentro e fora, entre visão e os outros sentidos e, sobretudo, expressão e uma mistura essencial que nos constitui como humanos.

Não poderia ter tema mais difícil de expressar-se em um texto. Nossa linguagem fragmenta e separa dentro de fora, corpo de mente, sentir de pensar. Mesmo ao tentar escrever a não dissocialidade, comumente compomos frases que envolvem dois polos, como a anterior.

Mais do que isso, Serres estava enfrentando o problema da sensação: mais do que entender a mistura, como conceito racional, e o corpo como este ente do pensar e sentir, ele precisava que o leitor, ao acompanhar seu escrito, sentisse propriamente isso.

No trecho a seguir lemos um pequeno fragmento do início do livro, o qual considero brilhante, no qual Serres consegue realizar tudo isso de forma vívida, permitindo a intuição do cerne de seu livro, misturando evocação, reinvocação, invocação, convocação e provocação em uma escrita poética, verossímil e de profunda ressonância no leitor.

Saber inútil até que chegue o verdadeiro dia de fúria; veio, sem aviso, num dia de inverno, no mar. $\mathrm{O}$ fogo roncava como um trovão aterrador, num minuto fecharam-se as portas estanques. Eu admirava os que se atiravam, sem pensar, pelas escadas, nos alçapões. Ouvi muito ruído e já não tenho lembrança.

De repente, estou só. O que aconteceu? No compartimento hermético, o calor insuportável faz desmaiar. É preciso sair. A porta, atrás, bloqueada definitivamente, volantes e alavancas em posição de estanque, trancadas pelo outro lado. Sufoco sob a fumaça espessa, deitado no chão movediço, sacudido pelas pancadas de mar. Então, a vigia, só resta a pequena vigia. Levantar-me sem respirar, tentar abrir os ferrolhos enferrujados que a interditam. Resistem, foram pouco usados, uma ou duas vezes, com certeza, desde o lançamento do casco. Não cedem. Deitar de novo para recobrar fôlego, rente ao chão. O tempo torna-se mais ameaçador como se a onda recuasse. Levantar outra vez, em estado de apnéia, e tentar outra vez soltar os ferrolhos que parecem ceder lentamente. Três, quatro vezes, não lembro mais, volto outras tantas ao chão, maxilares crispados, músculos paralisados, insisto, insisto, a janela fechada. Bruscamente se abre. [...]

Fiquei lá dentro, imóvel, vibrando, pregado, gesticulando em torno da coleira fixa que me comprimia, por tempo bastante longo para meditar, não, para que meu corpo aprendesse para sempre a dizer "eu" em toda verdade. De verdade, sem nunca poder se enganar. Sem erro, convictamente, porque esta meditação sombria e lenta, fulminante, decidia, simplesmente, a vida. Estou dentro, queimado, carbonizado, só a cabeça de fora, gelada, tiritante, ofuscada. Estou dentro, expulso, excluído, a cabeça e o braço, um ombro só, o esquerdo primeiro, estão de fora, na tempestade desencadeada. Dentro, no meio do fogo louco que se expande, o todo preso em uma coleira de angústia, a cabeça e o segundo ombro a custo desprendido saem, entregues à tormenta. Não estou salvo, ainda nem saí, aprisionado ainda, todo em um único lado da janela, o aro de cobre aberto no flanco do navio incendiado não tem a dimensão do círculo comprimido do tórax. Ainda dentro, mesmo que a cabeça e os dois ombros apontem no inverno. A vida comprime o peito à beira do esmagamento. É isto, vou morrer. Não consigo 
apoiar o pé em lugar algum, atrás, no inferno da queimadura onde ainda estou, os braços colados ao corpo não servem para nada, fiapo de palha enfiado num buraco, sem poder avançar, sem esperança de voltar atrás, vou morrer de sufocamento. Ou não respirar na fumaça, ou não respirar ante o vento gelado, ou não respirar no meio da coleira enferrujada, não consigo sequer decidir.

Então, uma pancada violenta de mar, mais oblíqua e seca, faz o aro passar por minhas costelas flutuantes. Sim, Deus seja louvado, estou fora. Inspiro o ar frio até desmaiar. Horror, o mar, mais feroz, expõe o fundo do barco a uma ressaca descontrolada. Ele se desequilibra pelo outro bordo, e cá estou eu, enfiado de novo até o meio, no círculo de ferro, estou dentro, ainda. Dir-se-ia que o casco passava sobre montes de pedras. Uma pancada de um bordo me libertava, uma pancada, de outro bordo, me reaprisionava.

$\mathrm{Eu}$ estava dentro, eu estava fora.

Quem, eu? (Serres, 2001, p. 12-13)

Dentro, fora, dentro: como saber a diferença?

\section{O imperativo estético vocativo como hermenêutica}

É um porto de chegada comum aos que trilham o pensamento fenomenológico a defesa da poética e da arte como linguagem para compreensão e revelação do ser, como os casos de Heidegger (2012b), Merleau-Ponty (2013) ou Bachelard (2009). O poético, no entanto, possui várias facetas, e aquela que é destacada por tais autores é sua capacidade de criação a partir de intuições, dos sentidos e da imaginação.

No caso da escrita, Van Manen (2014) menciona um imperativo estético, que se refere a este cuidado com a escrita, cuja estética é crucial na tarefa de levar a cabo o projeto fenomenológico. Uma estética fenomenológica, no caso, refere-se à questão da forma de expressão e sua autenticidade em relação ao fenômeno a ser desvelado. Para isso, devemos assumir a voz do texto, para que ela se propague por esta estética, enquanto forma própria de composição.

Adotar uma estética, no entanto, não é livre de riscos. Como lemos na epígrafe deste texto, do autor português Gonçalo Tavares, todo sentido estético se torna por fim atitude natural. Por isso, assim como os fenômenos e o pensar, ela não pode se converter em um padrão ou modelo, mas deve ser coerente ao movimento vivo do mundo e das experiências. A estética, fenomenologicamente compreendida, deve ser resultado da poiésis, ou seja, uma criação.

Assim se vislumbra a ligação fundante entre escritamundo-experiência: pensar nesta estética, ou seja, neste sentido do texto, compreendendo este momento como o decisivo na realização da fenomenologia: a composição que permite, na escrita-leitura, como ato único, o pensarsentir o fenômeno.

Michel Serres o fez de forma potente, trazendo assim não apenas inspiração para pensar uma escrita fenomenológica, justamente por sua busca pela experiência e pelo sentir, fazendo de seu texto algo pulsante, vivificado por uma escrita vocativa por excelência. Com isso a própria leitura se torna uma experiência de desvelamento, uma abertura de manifestação e compreensão.

Uma ciência geográfica que seja fenomenológica deverá enfrentar os desafios da linguagem e a busca por uma escrita vocativa, na qual a circunstancialidade do ser-no-mundo seja a potência criadora e doadora de sentido, abrindo-se para o compartilhamento de experiências e a possibilidade da própria leitura converter-se em uma experiência.

Isso não significa descartar a escrita moderna, nem abrir mão da razão. Muitos veem neste imperativo estético uma guinada unilateral para a poética, como se esta fosse a única forma de escrita possível para a fenomenologia. Na realidade, mais do que o poético, que se constitui como uma das vias para a qual apontam muitos fenomenólogos (Dufrenne, 1969; Nunes, 1986; 1999; Bosi, 2008), o caminho que vislumbro na busca por uma escrita fenomenológica, especialmente no contexto da geografia, é a de um texto que esteja na proximidade com a mundanidade, ou seja, com a própria geograficidade, tal como compreendida por Dardel (2011). A questão não é estética no sentido dado a este termo na tradição filosófica ou da própria ciência da arte (Dufrenne, 1982): antes, trata-se de uma preocupação que remete à forma e à sua proximidade com a experiência, com o vivido, mais ligada à preocupação heideggeriana de desvelamento do Ser (Heidegger, 2012b), ou a expressão sensível-senciente do originário, como em Merleau-Ponty (2007). Em qualquer um destes pensamentos, a questão da forma remete à relação do ser-no-mundo, implicando a necessidade de uma compreensão desta indissocialidade originária na constituição dos próprios fenômenos.

Isso nos coloca um grande desafio que não se realiza simplesmente com a capacidade estética ou poética, mas sim, com uma superação, no sentido heideggeriano de Verwingdung (Heidegger, 1999), da linguagem que oculta o sentido das coisas, afastando-nos de sua mundanidade. Verwingdung remete à ideia de uma ultrapassagem, ou seja, não o vencimento de uma etapa que descarta as anteriores. Antes, segundo Vattimo (2007), o uso deste termo em Heidegger remete a uma ideia de ultrapassagem que aceita e aprofunda o anterior em um movimento de ressignificação. Neste sentido, mesmo considerando o movimento do pensamento fenomenológico como herdeiro da tradição da modernidade, especialmente em Heidegger podemos vislumbrar o movimento de ultrapassagem que não implica rompimento com a tradição, mas o esforço de repensá-la e resignificá-la, o que traria, na concepção de Vattimo (2007), elementos para 
se compreender tal pensamento como ultrapassagem da própria modernidade.

O imperativo estético vocativo, portanto, pode ser compreendido nestes termos: uma ultrapassagem da escrita proposta pela ciência moderna, como aprofundamento e ressignificação, mas não como superação que implica o descarte de toda a tradição. Trata-se de um caminho para que o texto possibilite, ele mesmo, a compreensão hermenêutica da facticidade, aproximando-o mais dos sentidos experienciados e vividos, permitindo assim aprofundar sua potência desveladora. Os métodos vocativos serão tanto mais eficientes quanto forem fundados ou reverberarem experiências: nesta facticidade é que reside sua potência hermenêutica e desveladora.

Assim, o desafio da linguagem tal como aqui formulado, não é apenas uma questão de forma e de estética: trata-se sobretudo de um problema epistemológico que se refere à própria hermenêutica e à possibilidade de compreensão dos fenômenos geográficos tal como são desvelados na experiência. A autointerpretação da facticidade, que Heidegger (2013) chama atenção, se refere à nossa própria mundanidade, o que nos provoca ao desafio de uma escrita que seja, ela própria, também mergulhada nesta mundanidade. A possibilidade da compreensão também se dá, ao final, na escrita-leitura.

Este desafio está posto a todos os que buscam na fenomenologia inspiração ou orientação para o desafiador do conhecimento. Este texto, no entanto, está mais próximo daquilo que Ihde (2012) denomina de "fazer fenomenologia”, diferenciando assim os fenomenologistas dos fenomenológos. O limite é, por suposto, tênue, mas está claro para mim que a tarefa que pesquisadores das ciências humanas e sociais tomam para si ao tentar pensar suas respectivas ciências a partir da fenomenologia aproxima-se pouco do filosofar fenomenológico, estando mais ligado a um fazer. É por isso que muitas das perguntas convertem-se em perguntas de método.

Isso não elimina os desafios, nem atenua a grande tarefa de repensar suas práticas científicas concebidas em outros fundamentos. Fazer fenomenologia, por exemplo, como geógrafo, envolverá uma reorientação, mas também percorrer novamente toda a tradição geográfica com outro olhar. Éric Dardel o fez em O homem e a terra, no capítulo sobre a História da Geografia: uma história fenomenológica (Dardel, 2011), permitindo novo olhar e novos sentidos para a própria história do pensamento geográfico.

A geografia que se revela neste desvelar, como abertura, torna possível outras aproximações. Assim, mesmo que hoje não me esgueire mais pelas bibliotecas, como fazia nos meus tempos de estudante, continuo entre livros, muitos dos quais acumulo em minha própria biblioteca. Perco-me entre pilhas, entre aquisições e empréstimos. Autores e narrativas povoam minha mente, as paredes de meu quarto, meu banheiro. Trazem evocações, invocações e muitas provocações e em todos eles, eu sinto a geografia.
Tais evocações não são maiores nem menores daquelas que sinto cotidianamente ao caminhar pelas ruas da cidade em que vivo ou ao viajar para outro continente. Contemplar uma elevação nos limites da cidade ou sentir o calor asfáltico-poluído-seco-denso da urbanidade me permitem, igualmente, este pensar-sentido, cuja estética cotidiana tem uma potência deflagradora.

O processo degenerativo, portanto, continua. Penso ser ele a razão da própria busca, e uma forma de manter-se alerta aos riscos da atitude natural. Depurar e despensar pode degenerar, mas com isso se abre a possibilidade da reinvocação.

\section{Referências}

Bachelard, G. (2003). A poética do espaço. São Paulo: Martins Fontes.

Bachelard, G. (2009). A poética do devaneio (A. P. Danesi, Trad.) São Paulo: Martins Fontes.

Bernal, D. A. (2015). A rosa do deserto: hidropoéticas do lugar no habitar urbano contemporâneo. Dissertação (Mestrado em Geografia) - Universidade Estadual de Campinas.

Besse, J. (2006). Ver a terra: seis estudos sobre geografia e paisagem. (V. Bartalini,Trad.) São Paulo: Perspectiva.

Bosi, A. (2008). O ser e o tempo da poesia. São Paulo: Cia. Das Letras.

Dal Gallo, P. M. \& Marandola Jr., E. (2015). O pensamento heideggeriano na obra de Éric Dardel: a construção de uma ontologia da geografia como ciência existencial. Revista da ANPEGE, v. 11, p. 173-200.

Dal Gallo, P. M. (2015). Ontologia geográfica à luz da obra de arte: o embate Terra-mundo em Out of Africa. Dissertação (Mestrando em Geografia) - Universidade Estadual de Campinas.

Dardel, E. (2011). O homem e a terra: natureza da realidade geográfica. (W. Holzer, Trad.) São Paulo: Perspectiva.

Dufrenne, M. (1969). O poético. (L. A. Nunes e R. K. de Souza, Trad.) Porto Alegre: Globo.

Dufrenne, M. (1982). A estética e as ciências da arte (A. Bravo, Trad.) Rio de Janeiro: Bertrand. v. 1 e 2.

Ferreira, R. B. (2016). O mundo-da-vida como fundamento vital para as políticas de adaptação. Dissertação (Mestrado Interdisciplinar em Ciências Humanas e Sociais Aplicadas) - Faculdade de Ciências Aplicadas, Universidade Estadual de Campinas.

Foucault, M. (2007). As palavras e as coisas: uma arqueologia das ciências humanas. (Trad. Salma Tannus Muchail) São Paulo: Martins Fontes, 2007.

Galvão, C. E. P. (2016). Por abismos... casas... mundos... a geosofia como narrativa fenomenológica da geografia. Dissertação (Mestrado em Geografia) - Instituto de Geociências, Universidade Estadual de Campinas. 
Gratão, L. H. B. (2012). Sabor \& Paisagem à Luz de Bachelard: convite para sentar-se à mesa. Geograficidade, v. 2, p. 30-41.

Heidegger, M. (1999). Identidade e diferença. Em Heidegger. São Paulo: Abril Cultural.

Heidegger, M. (2001c). Ciência e pensamento do sentido. Em Heidegger, M. Ensaios e conferências (p. 39-60). Petrópolis: Vozes.

Heidegger, M. (2001a). Construir, habitar, pensar. Em Heidegger, M. Ensaios e conferências (p. 125-141). Petrópolis: Vozes.

Heidegger, M. (2001b). “...poeticamente o homem habita...”. Em Heidegger, M. Ensaios e conferências (p. 165-181). Petrópolis: Vozes.

Heidegger, M. (2001d). O que quer dizer pensar?. Em Heidegger, M. Ensaios e conferências (p. 111-124). Petrópolis: Vozes.

Heidegger, M. (2012a). Ser e tempo (F. Castilho, Trad.) Campinas: Ed. da UNICAMP.

Heidegger, M. (2012b). A origem da obra de arte. Em Heidegger, M. Caminhos de Floresta (p. 5-94). (I. Borges-Duarte, Trad.). Santa Maria da Feira: Fundação Calouste Gulbenkian.

Heidegger. M. (2013). Ontologia (Hermenêutica da facticidade). (R. Kirchner, Trad.). Petrópolis: Vozes.

Husserl, E. (2012). A crise das ciências europeias e a fenomenologia transcendental: uma introdução à filosofia fenomenológica. (D. F. Ferrer, Trad.). Rio de Janeiro: Forense Universitária.

Ihde, D. (2012). Experimental phenomenology: multistabilities. 2. ed. Albany: State University of News York Press.

Malpas, J. (2008). Heidegger's topology: Being, Place, World. Cambridge: MIT Press.

Marandola Jr., E. (2016). Identidade e autenticidade dos lugares: o pensamento de Heidegger em Place and placelessness, de Edward Relph. Geografia (Rio Claro. Impresso), v. 41, p. 5-15.

Marandola Jr., E. (2012). Heidegger e o pensamento fenomenológico em Geografia: sobre os modos geográficos de existência. Geografia (Rio Claro. Impresso), v. 37, p. 81-94.

Merleau-Ponty, M. (2013). O olho e o espírito. (P. Neves \& M. E. G. G. Pereira, Trad.). São Paulo: Cosac Naify.

Merleau-Ponty, M. (2012). A prosa do mundo. São Paulo: Cosac Naify.

Merleau-Ponty, M. (2007). O visível e o invisível (J. A. Gianotti e A. M. d'Oliveira, Trad.) São Paulo: Perspectiva.

Nunes, B. (1986). Passagem para o poético. Filosofia e poesia em Heidegger. São Paulo: Ática.

Nunes, B. (2007). Hermenêutica e poesia: o pensamento poético. Belo Horizonte: Ed. UFMG.

Ricouer, P. (2010). Tempo e narrativa (C. Berliner, M.VM. de Aguiar, Trad.) São Paulo: Martins Fontes. (3V.)

Serres, M. (2001). Os cinco sentidos: filosofia dos corpos misturados. Rio de Janeiro: Bertrand Brasil.
Serres, M. (1997). Atlas. Lisboa: Instituto Piaget.

Serres, M. (1996). Diálogo sobre a ciência, a cultura e o tempo: conversas com Bruno Latour. Lisboa: Instituto Piaget.

Stengers, I. (2002). A invenção das ciências modernas (Trad. Max Altman). São Paulo: Ed. 34, 2002.

Tavares, G. (2003). A máquina de Joseph Walser. Alfragide: Caminho.

Van Manen, M. (2014). Phenomenology of practice: meaning-giving methods in phenomenological research and writing. Walmut Creek: Left Coast Press.

Vattimo, G. (2007). O fim da modernidade: niilismo e hermenêutica na cultura pós-moderna. (E. Brandão, Trad.) São Paulo: Martins Fontes.

Eduardo José Marandola Júnior - Graduado em Geografia pela Universidade Estadual de Londrina, Doutor em Geografia pelo Instituto de Geociências da Universidade Estadual de Campinas, Professor Associado da Faculdade de Ciências Aplicadas da Universidade Estadual de Campinas (Campus Limeira), Coordenador do Laboratório de Geografia dos Riscos e Resiliência (LAGERR), do Centro de Ciências Humanas e Sociais Aplicadas (CHS) e o Curso de Mestrado Interdisciplinar em Ciências Humanas e Sociais Aplicadas (ICHSA). Editor da revista eletrônica Geograficidade, do Grupo de Pesquisa Geografia Humanista Cultural (UFF/CNPq); Líder do Grupo de Pesquisa Fenomenologia e Geografia (FCA/Unicamp) e Vice-Líder do Grupo de Pesquisa Métodos Mistos e Análises Multiníveis (FCA/Unicampo). Endereço Institucional: Faculdade de Ciências Aplicadas da Unicamp. Caixa Postal 1068. CEP: 13480-970. Limeira, SP. E-mail: eduardo.marandola@fca.unicamp.br

Recebido em 25.04.2016 Primeira Decisão Editorial em 22.08.2016 Aceito em 29.08.2016 